\title{
DICHOSOS LOS POBRES
}

Raúl Condori Cutimbo*

\section{RESUMEN}

Este artículo es una exégesis reflexiva sobre "La bienaventuranza a los pobres" en el contexto social de América Latina y en especial para nuestro Perú, reflexión que puede inquietar por la misma situación socio-económica, cultural y política en que vivimos. Pareciera que la realidad misma de la pobreza cuestionara la distancia que relativiza la importancia de toda aproximación puramente "temática". El análisis y las reflexiones que a continuación se presentan no pretenden buscar una solución a este problema tan complejo y real. El objetivo es fundamentalmente de carácter exegético: comprender el mensaje de un texto escrito hace muchos años, en un ambiente socio-cultural muy distinto al nuestro, pero cuyo contenido sigue siendo actual, por su carácter provocativo y desconcertante, teniendo en cuenta que no se puede hacer exégesis sin mirar el texto desde la realidad en que se vive.

\section{PALABRAS CLAVE:}

Bienaventuranzas, Pobreza, Reino de Dios, Exégesis, Bienaventurados los pobres.

\section{BLESSED ARE THE POOR}

\begin{abstract}
This article is a thoughtful exegesis on "The beatitude of the poor" within the social Latin American context, and specifically of Peru. This in sight may worry because of the socio-economic, cultural, and political situation we live in, where the reality of the poor seems to question and thus undermine the relevance of any approximation that is purely "thematic". The analysis and insights presented herein are not intended to seek a solution to such complex and real problem. The purpose is primarily one of exegetical character: to understand the message of a text written many years ago -in a socio-cultural environment that is very different from ours -but with a content that is still current for its provocative and puzzling nature, considering that no exegesis can bed one without understanding the text with in the reality one lives in.
\end{abstract}

\section{KEYWORDS:}

Beatitudes, Poverty, Kingdom of God, Exegesis, Beatitude of the Poor.

\footnotetext{
* Bachiller en Teología por la Pontificia Universidad Salesiana de Roma. Licenciado en Educación en la especialidad de Filosofía y Ciencias Sociales por la Universidad Nacional Mayor de San Marcos. Cuenta con Postgrado en Administración educativa. Docente UNIFÉ.
} 
L a palabra pronunciada después de la unción de Jesús en Betania: "Pobres tendréis siempre entre vosotros" (Mc 14, 7), era una verdad de experiencia diaria en el ambiente de la Palestina de hace más de 2000 años. Esta misma palabra no ha perdido nada de su triste validez para casi ninguna sociedad. Más aún, bien se puede decir que la realidad de la pobreza y el empobrecimiento gradual de algunos grupos sociales ha adquirido hoy una dimensión dramática que no puede dejar indiferente a nadie con algo de responsabilidad social, y mucho menos a los cristianos que desean tomar en serio el mensaje de Jesús.

Entonces ¿Qué sentido puede tener proclamar felices a los pobres? Si la pobreza es carencia, ¿puede considerarse esta carencia en una forma tan positiva que ella constituya la base para una "bienaventuranza"? ¿No es justamente esta forma positiva de valorar una carencia la que ha llevado a justificar injusticias y miserias escandalosas? De ahí que se han realizado tantas críticas, desde diferentes ópticas filosóficas como la marxista que dice que son formas alienantes provocadas por la religión, o las observaciones aún más profundas de Nietzsche sobre la valoración cristiana de no-valores; estos hechos nos hacen dar cuenta que la bienaventuranza a los pobres encierra graves problemas de comprensión para el hombre de hoy.

El creyente se enfrenta aquí con una palabra cuya comprensión adecuada es decisiva si se quiere entender el lenguaje y la intención de Jesús. ¿En qué relación está la bienaventuranza a los pobres con el mensaje central de Jesús, es decir con el anuncio de la irrupción en la historia del poder salvador de Dios?

Más allá de la pregunta por la coherencia interna del discurso teológico de Jesús, la bienaventuranza a los pobres plantea otra, más inmediata y directa que toca a la persona misma de Jesús. ¿Qué sentido de la realidad tenía el profeta de Nazareth que lo hacía proclamar felices a los pobres y hambrientos, o invitar a admirar los lirios del campo y los pájaros del cielo como testimonio del amor providencial del Padre celestial? ¿Acaso ignoraba la realidad acuciante de la indigencia, a la que una referencia tan explícita a la bondad protectora de Dios hubiera resultado simple sarcasmo y ocasión de blasfemia? ¿O hay que interpretar esto como la ingenua falta de experiencia de alguien a quien le ha ido demasiado bien en la vida, y que nada sabe de aquel momento crítico en que el hambre aprieta y Dios no responde? ¿Quién es este Jesús que habla de esta manera? En el presente análisis se quiere aclarar, de alguna manera alguna de estas y otras preguntas que nos suscita interrogantes, por ello queremos abordar algunos aspectos muy puntuales desde los evangelios para ir entrando en la temática del análisis de la bienaventuranza a los pobres desde una visión actual.

\section{Los Evangelios y sus Destinatarios}

\subsection{El Evangelio según San Marcos}

Las comunidades en las que surge el evangelio de Marcos parecen ser de origen pagano, por lo que su autor se preocupa en explicar las costumbres judías. Parece ser que viven en una situación difícil en la que se critica su fe. Probablemente este evangelio terminó de redactarse en su forma definitiva hacia el año 70, poco antes de la destrucción del Templo de Jerusalén. La tradición lo atribuye a JuanMarcos, compañero de Bernabé y Pablo, y posteriormente de Pedro.

Es un evangelio que nos presenta a un Jesús tremendamente cercano a nosotros, que enseña más con los hechos que con las palabras. Utiliza la geografía teológica- 
mente, oponiendo Galilea, imagen de los paganos, a Jerusalén, el pueblo judío que rechaza al Mesías. El proyecto de este evangelio es que el lector confiese junto con el soldado romano al pie de la cruz "verdaderamente este hombre era Hijo de Dios".

\subsection{El Evangelio según San Lucas}

Este evangelio está dirigido a las comunidades cristianas de Siria, de Grecia o de Asia menor, que eran tremendamente pobres. Hay que tener en cuenta que es la primera parte de una obra en dos tomos: evangelio y Hechos de los Apóstoles. Su forma definitiva la adquirió en torno al año 80, y parece tener como autor a Lucas, compañero de Pablo y griego de lengua, cultura y formación.

Es un evangelio que insiste mucho en el cariño entrañable de Dios por todos los hombres, en especial por los más pequeños, pobres y desamparados. Al mismo tiempo, da el título de Señor a Jesús, no sólo resucitado, sino ya en su vida mortal. Para sus comunidades, que vivían en ciudades donde se daba culto al emperador, esto tenía especial significación.

Presenta al Resucitado insistiendo especialmente en su corporalidad, haciendo ver que es toda la persona la resucitada, y no sólo el alma lo que permanece, según creían los griegos de su tiempo.

\subsection{El Evangelio según San Mateo}

Las comunidades de Mateo parecen compuestas por cristianos procedentes del judaísmo, que vivían en Siria-Palestina, por lo que utiliza más que los otros evangelistas la Escritura. Son comunidades que han entrado en conflicto con el judaísmo oficial y que se abren a los paganos, herederos de la promesa. En su base está la personalidad de Mateo, aunque su última y definitiva redacción se llevará a cabo entre los años 80 y 90.

Este evangelio está preocupado por la enseñanza que Jesús trajo y ahora Mateo desea poner de manifiesto de manera sencilla y asequible a un público que se mueve dentro de las categorías vitales del judaísmo, también ofrece pistas en torno a la organización, la vida fraternal, etc., de la Iglesia, por lo que se le ha llamado también "el evangelio eclesial" puesto que es el único evangelio que trae el término "Ekklesia" $(16,18 ; 18,17)^{46}$

\section{Contexto de las bienaventuranzas}

Antes de acercarnos al texto directo sobre la bienaventuranza de nuestro interés, nos será de ayuda citar algunos aspectos generales del contexto histórico y literario en que ubicamos estas palabras de Jesús, que nos faciliten una comprensión más profunda.

Encontramos el discurso de las bienaventuranzas al comienzo del sermón de la montaña (porque Jesús subió a la montaña y desde allí dirige su mensaje a sus oyentes) en el evangelio de Mateo (Mt.) o si seguimos el texto en Lucas (Lc.), iniciando el sermón de la llanura (ya que dice que el Señor bajó de la montaña y desde ahí pronunció su discurso).

En ambos encontramos una introducción que arroja un cierto ambiente de solemnidad a las palabras de Jesús: Mateo 5:1 2: "Y cuando vio las multitudes, subió al monte; y después de sentarse, sus discípulos se acercaron a Él". En Lucas 6:20: expresa "Volviendo su vista hacia sus discípulos decía: "Bienaventurados los pobres, porque vuestro es el Reino de Dios". Tanto Mateo como Lucas sitúan el sermón

46 Cfr. Maté Rico, Antonio. (1996). Palabra de Dios. pp.59-74. 
que contiene las bienaventuranzas al comienzo del ministerio público de Jesús, que en el evangelio de Mateo tiene una visión general basada en la predicación del Reino, incluyendo una enseñanza que nos lleva irremediablemente a la acción, a la praxis de lo que constituye la voluntad de Dios para su pueblo, la esencia del anuncio del evangelio del Reino de Dios. El sermón de la montaña es una expresión pura, universal, de la voluntad de Dios en la línea de la ley y los profetas, es decir, tal como fue siempre. En este sentido formula las "condiciones de admisión en el reino de Dios." 47

\section{La redacción de los dos evange- listas}

\subsection{Las dos versiones sobre la bien- aventuranza: Mateo 5,3 Y Lucas 6, $20 b$}

Las diferencias que ofrecen las dos versiones son pequeñas pero significativas. El texto de Mt 5, 3 dice: "Felices los pobres en el espíritu porque de ellos es el Reino de los cielos". El texto de Lc 6, 20b: "Felices los pobres, porque vuestro es el Reino de Dios". Mateo formula la bienaventuranza en la tercera persona y le da así el carácter de una enseñanza de valor general. Lucas en cambio ubica a Jesús frente a un auditorio de pobres a quienes se les anuncia la bienaventuranza y su fundamentación: ustedes los pobres son felices porque les pertenece el Reino de Dios. La diferencia más notable no consiste sin embargo en el tono más o menos directo de dirigirse al auditorio, sino en la determinación de los pobres. Lucas habla simplemente de los pobres. Uniendo a esto la amenaza formulada en LC 6, 24: "iAy de vosotros los ricos, porque ya tenéis vuestro consuelo!", hay que entender en los pobres de Lc 6; $20 \mathrm{~b}$ a los materialmente pobres, a los indigentes y hambrientos (LC 6, 21).

Contrastando con la concretes de los destinatarios que Lucas nos ofrece, Mateo realiza una precisión importante tal como nos hará notar H. Lona: Los pobres "en el espíritu" (to pneumati) son los dichosos. Aunque no dicho en forma explícita la expresión marca una cierta distancia con respecto a la pobreza como realidad inmediata, de la que hablaba Lucas. En la intención de Mateo no es el pobre sin más el bienaventurado, porque a él le pertenece el Reino de los cielos, sino el pobre "en el espíritu". La expresión deja abierto incluso si esta pobreza interior del hombre ante Dios, tiene que estar acompañada necesariamente por los signos reales de carencia que marcan el perfil de la pobreza como hecho sociológico ${ }^{48}$. Después de constatar las diferencias entre estas dos versiones, tendremos que explicar el sentido real de cada una de ellas en el contexto de las Escrituras.

\subsection{Lucas 6, 20b y la Versión de Lucas}

El hecho más importante de las bienaventuranzas en la versión de Lucas es la contraposición de las cuatro bienaventuranzas $(6,20 b-23)$ con los cuatro ayes de amenaza (6,24-26). En una especie de explicación recíproca ambos textos se complementan mutuamente. Las tres primeras bienaventuranzas -desde el punto de vista del origen tradicional ciertamente las más antiguas muestran una relación temporal compleja. La posesión del Reino atribuida a los pobres fundamenta su felicidad. La afirmación está hecha en presente: porque vuestro es el Reino de Dios.

47 Cfr. Chevrot, Georges. (1989). Las bienaventuranzas. pp52-68.

48 Cfr. Lona, Horacio. (1998). Las bienaventuranzas. pp.8-9 
En las dos bienaventuranzas siguientes aparece un futuro escatológico: los hambrientos serán saciados y los que lloran reirán. Futuro escatológico quiere decir que su cumplimiento se dará sólo al fin de los tiempos, y que no es producto de la planificación o de los esfuerzos humanos. Con todo, ese futuro de Dios no debe ser pensado como una dimensión que en cuanto futuro no está aún presente y es sólo objeto de la esperanza. Paradójicamente ese futuro proyecta su vigencia en el presente y hace que los hambrientos y los que lloran ya ahora sean proclamados felices $^{49}$.

Algunos exegetas como J. Jeremías nos refieren que es conocido el interés de Lucas por responder a los nuevos problemas que plantean ciertas comunidades de Asia Menor entre los años 80 y 90 . Uno de estos problemas estaba dado por la existencia de cristianos de un nivel cultural más alto y de una posición económica mejor si se toma como punto de comparación lo que era el nivel de las comunidades cristianas más antiguas. Así, por ejemplo, la forma en que Lucas introduce sus dos obras, el Evangelio y los Hechos de los Apóstoles (Lc 1, 14 y Hech 1, 1-2) responde a las exigencias literarias de un culto lector helenista de su tiempo. Otros trozos de la obra lucana en los que el autor puede mostrar la calidad de su estilo responden igualmente a esta preocupación.

Pero más notorio aún es el problema creado por cristianos pudientes en las comunidades a las que se dirige el evangelista nos dice J. Jeremías; Lucas cuenta con material variado de sus fuentes propias -son textos que no aparecen en ninguno de los otros Evangelios-, como el relato del pobre Lázaro (Lc 16, 19-31) o la parábola del rico necio (12, 16-21). En otros casos se trata de textos redaccionales en los que exhorta a los ricos a no olvidar a los pobres y ayudarlos en sus necesidades. Es bienaventurado aquel que no invita a quienes pueden retribuirle la invitación, sino a los pobres y desvalidos. Su recompensa tendrá lugar en la resurrección de los justos (14, 12 14). No es ninguna casualidad cuando en la versión que Lucas ofrece de la parábola del gran banquete $(14,16-24)$ la lista de los invitados después del rechazo de los que originariamente estaban previstos, corresponde exactamente a la lista de aquellos a quienes preferencialmente hay que invitar a comer: los pobres, los lisiados, los cojos, los ciegos (Lc. 14, 13 y 14, 21). Lucas aprovecha la parábola del gran banquete para repetir la exhortación a los ricos para que recuerden su responsabilidad por el cuidado de los pobres y necesitados.

Los ejemplos del rico necio y del pobre Lázaro muestran el peligro de la riqueza. En un caso se cae en una falsa valoración de la realidad poniendo toda la confianza en un bien efímero, pasajero. La realidad de la muerte pone fin al error en cuanto lo hace irremediable. En el otro caso se subraya el efecto enceguecedor de la riqueza que impide al rico ver la realidad del pobre Lázaro tirado a su puerta. El enceguecimiento es tan grande que pareciera excluir la posibilidad de conversión: "Si no escuchan a Moisés ya los profetas no se convencerán ni aunque resucite uno de entre los muertos" (LC 16, 31).

Pero Lucas no se contenta sólo con mostrar los peligros de la riqueza, sino que ofrece también a los ricos un camino de salvación. En ese sentido merece no sólo el título de "evangelista de los pobres", sino que podría llamarse -acaso

49 Cfr. Ruiz de la Peña, Juan. (1986). La otra dimensión, pp. 64-65. 
con más fundamento- el "evangelista de los ricos" como nos recuerda y lo llama G. Chevrot en sus reflexiones en torno a las bienaventuranzas ${ }^{50}$.

El camino propuesto por Lucas es el de la ayuda concreta a los pobres, especialmente en la forma de la limosna. Ella es el medio para obtener un tesoro en el cielo (Lc 12, 33). En el contexto de la preocupación pastoral de Lucas por mostrar a los ricos un camino de salvación, la bienaventuranza a los pobres con su tono directo y, en fuerte contraste con ella, la amenaza a los ricos, pareciera escaparse de la línea trazada por el evangelista. Pues la sucesión de bienaventuranza y amenaza no tiene carácter exhortativo. En ella se expresa una urgencia y perentoriedad que no admite réplicas ni casuística. Con todo, sería erróneo hablar de una inconsecuencia temática dentro del macro contexto de la obra lucana ${ }^{51}$.

El evangelista es un fiel receptor de las diversas tradiciones de las que dispone transmitidas en el cristianismo primitivo. Una de ellas eran los dichos de origen fundamentalmente jesuánico en los que se expresaba con radicalidad profética la necesidad de abandonado para seguir a Jesús sin anteponer nada a ello (Lc 18, 22 y los paralelos Mc. 10,21; Mt 19, 21; ver también Lc 16, 13; Mt $6,24)$. Era realmente la situación de los primeros discípulos que habían dejado el lugar de trabajo, el hogar y lo que poseían para seguir al Señor (Mc 10,28; Lc 18,28; Mt 19, 27). Frente al llamado a seguir a Jesús en esas condiciones la riqueza podía constituirse en un impedimento que explica bien el juicio de Jesús al respecto: "iQué difícil es para los que tienen riquezas entrar en el Reino de Dios!" (Mc 10, 23; Lc 18, 24; Mt 19, 23).
Lucas no disminuye en ninguno de estos dichos la radicalidad de la exigencia. Se trataba en esas tradiciones de palabras de Jesús que a sus ojos no habían perdido nada de su validez. Pero esas mismas tradiciones hablaban de personas que habían ayudado a Jesús y a sus discípulos compartiendo con ellos sus bienes, pero sin renunciar completamente a la posesión ni adoptar la forma de vida de los predicadores itinerantes propia del grupo de los discípulos más inmediatos. Lucas es el único que habla de algunas mujeres que servían a Jesús con sus bienes, y cita entre ellas a Juana, la mujer de Cusa, un administrador de Herodes (Lc 8,2-3). Esto que tenía ya vigencia en los tiempos de Jesús va a ganar después en importancia en la institución de las comunidades domésticas, es decir, en las casas que servían de punto de reunión y apoyo misionero en las diversas comunidades cristianas. Ya Pablo da un testimonio elocuente de la función e importancia de esta estructura y este modo de vida (Rom 16, 1; 16,5; 16, 23; Film 1s; Col 4, 15).

Así se entiende que el evangelista pueda transmitir tradiciones distintas sobre la exigencia de la pobreza sin encontrar en ellas ningún tipo de oposición. El respeto a la tradición más antigua no le hacía olvidar la situación peculiar de sus comunidades. Incluso para los cobradores de impuestos y para los soldados ofrece un camino de salvación (Lc 3, 12-14). Si lo dicho hasta ahora sobre la redacción de Lucas es acertado, hay que concluir de ello que su versión de la bienaventuranza a los pobres y la sucesión de bienaventuranzas y amenaza reproduce con fidelidad la tradición de la que depende, o sea la tradición transmitida en la colección de dichos del Señor ("Q" fuente de los logia) que conforma el estrato tradicional 
inmediatamente anterior. Históricamente es menos probable que sea él mismo quien radicalizara de tal modo la exigencia de la pobreza si es que estaba tan interesado en ofrecer también a los ricos una posibilidad de vida cristiana.

Horacio Lona nos advierte que un ejemplo sobre este modo de pensar y que nos puede clarificar la intención del evangelista es el relato parabólico del administrador infiel (Lc 16, 1 -8), tiene todas las características de la fantasía creadora y la originalidad de Jesús. El protagonista, cuya moralidad deja que desear, no vacila en engañar nuevamente a su patrón cuando advierte que se ha descubierto el despilfarro de su administración. La intención original del relato no es moralizante, y cualquier intento de justificación del administrador infiel hace las cosas aún más difíciles. La sorprendente reacción del hombre rico engañado por su administrador -lo alaba por su sagacidad $\sim$ no se refiere a la cualidad moral de la acción, sino a la capacidad de decisión de quien, sabiéndose perdido, recurre a un medio extremo para salvarse y con ello lo arriesga todo -para ver ganado todo-. La parábola pertenece a las así llamadas "parábolas de decisión", con las que Jesús ilustraba la necesidad de una decisión existencial para ir en su seguimiento, y al mismo tiempo, por medio de la narración, movía a ello. Relatos semejantes no tienen una intención ilustrativo-cognitiva, sino dinámica, en cuanto mueven a una determinada acción ${ }^{52}$.

En un texto al que ya hemos hecho referencia (Lc 16,9) el evangelista exhorta a dar limosna como correcto medio de utilización del dinero. El texto siguiente aparece en clara contradicción con el contenido de la parábola. Aquí se trata de ser fieles en lo poco, para merecer algún día mucho más. La fidelidad en el dinero de la iniquidad es garantía de fidelidad en la administración de los bienes verdaderos (16, 10-12). iBien puede decirse que el ideal aquí es el del administrador fiel! La discrepancia con la figura del administrador infiel que al fin recibe la alabanza de su señor no puede ser mayor. Pero no se trata de incoherencia. El peso de las tradiciones más antiguas no desvía la mirada del evangelista de las necesidades de las comunidades a las que escribe. De este modo se comprende el fenómeno tan peculiar de la recepción de una tradición en la que partiendo de una parábola de decisión, cuyo protagonista es un administrador infiel, se llegue a la figura de un administrador fiel de los bienes terrenos como condición para adquirir los eternos.

Análogamente a lo indicado a raíz de la bienaventuranza a los pobres y la amenaza a los ricos en Lc 6, 20b.24 es lógico pensar que no es Lucas el autor de la parábola. Ella estaba contenida en sus fuentes particulares y no correspondía a lo que el evangelista esperaba propiamente de un administrador. El respeto a la tradición lo lleva a transmitirla, el interés por la situación de su comunidad lo lleva a darle al final otro sentido. Inmediatamente después del relato de las tentaciones en el desierto (Lc 4, 1 13) el evangelista crea una escena en la que describe el solemne comienzo de la actividad pública de Jesús.

En la sinagoga de Nazaret, Jesús se presenta como aquél en quien se cumple el anuncio profético: él es el Mesías ungido por el Espíritu de Dios, enviado para dar la buena noticia a los pobres (Lc 4, 16-21). El texto es de extrema importancia para entender el anuncio cristológico de Lucas: Aquí se anuncia quién es Jesús, cuál es su mensaje y su misión, y se apunta ya 
en forma prefigurativa al rechazo que va a sufrir de parte del judaísmo oficial. La perícopa es algo así como un breve resumen del programa y de la historia de Jesús.

Esto hace ver que la bienaventuranza a los pobres no puede ser considerada como una concesión a la tradición. Es cierta la cuestión del origen de las bienaventuranzas en la versión de Mateo, y luego en la pregunta por el anuncio de la bienaventuranza en labios de Jesús.

\subsection{Mateo 5,3 y la versión de Mateo.}

Según observación de E. Lohse ${ }^{53}$ nos refiere que la bienaventuranza a los pobres según Mateo abre una serie de nueve bienaventuranzas a la que no se contrapone ninguna serie de ayes de amenaza como en el texto de Lucas. Pues si seguimos la comparación de Lucas y Mateo es posible constatar y darnos cuenta que Mateo tiene su propia línea. También los hambrientos son proclamados felices, como en Lc. 6, 21, pero el texto de Mt 5, 6 dice: "Felices los que tienen hambre y sed de justicia, porque ellos serán colmados". A diferencia de Lucas que falta el tono directo de la interpelación en segunda persona, y el objeto del hambre es la justicia, no el hambre material. La cercanía estructural con su versión de la bienaventuranza a los pobres salta a la vista. Para Mateo no son ni la pobreza ni el hambre tomada en su concretez y materialidad los que merecen la bienaventuranza, sino actitudes determinadas que no se confunden con la facticidad de la carencia, sino que suponen una intencionalidad específica.

Esto no quiere decir que las bienaventuranzas de Mateo signifiquen una espiritualización tal que pierdan ya su relación con la realidad de la carencia. Difícilmente
Mateo separó la actitud interior de la realidad material. Pero su interés no se dirige primariamente a confrontar al lector de su evangelio con el hecho paradójico de la elección de los pobres y necesitados como portadores del beneplácito de Dios, sino a moverlos para que adopten las actitudes que se encuentran reflejadas en su versión de las bienaventuranzas.

Un ligero examen de las otras bienaventuranzas confirma este juicio. Mateo no habla como Lc 6, 21 b de la felicidad de aquellos que ahora lloran, porque luego reirán, sino de los tristes o afligidos que serán consolados (Mt 5,4). La provocante tensión entre el llanto de los que ahora son proclamados felices y la alegría escatológica expresada en su reír, se ve reducida a la realidad de la aflicción y a la promesa del consuelo.

De las bienaventuranzas que no tienen ningún paralelo en Lucas merece consideración Mt 5, 10: "Felices los perseguidos a causa de la justicia porque de ellos es el Reino de los cielos". En realidad afirma J. Jeremías, se trata de una bienaventuranza cuyo contenido está expresado en el versículo siguiente: "Felices sois cuando os injurien y persigan y digan todo mal contra vosotros por mi causa" (Mt 5,11). Con la bienaventuranza en el v. 10 Mateo ha querido concluir propiamente "su" versión de las bienaventuranzas. Así se entiende la repetición: "Porque de ellos es el Reino de los cielos", que retorna la primera bienaventuranza en 5,3, y la mención otra vez de la justicia", que compendia en su teología la realidad de la buena noticia de la salvación. Solo la persecución a causa de esta justicia merece la bienaventuranza y la posesión del Reino ${ }^{54}$.

Un análisis más cercano de las bien-

53 Lohse, Eduard. (1985). Introducción al Nuevo Testamento, pp.151-155

54 Jeremías, Joachim. (1989). ABBA, el mensaje central del Nuevo Testamento, pp. 248-249. 
aventuranzas según Mateo podría demostrar que aquellas palabras que no tienen ninguna correspondencia en la versión de Lucas son secundarias y, en el contexto actual, de cuño redaccional. Entonces queda por preguntarnos ¿Cuál es el acento peculiar de la versión de Mateo? ¿Quiénes son los destinatarios de su mensaje? ¿Cuál es la situación comunitaria que sirve de trasfondo histórico a esta palabra?

Ante todo son necesarias algunas reflexiones preliminares.

La pobreza es una realidad social. Llamar bienaventurados a los pobres poniendo como motivación la posesión del Reino de Dios, es una valoración religiosa del hecho social de la pobreza. El radical tono profético de la versión de Lucas proclama bienaventurados a los pobres porque de ellos es el Reino de Dios. La pobreza aparece aquí interpretada en una forma básicamente positiva. Lo que permite esta valoración positiva de la pobreza no es su realidad sociológica, sino su relación con el Reino. iPero no se pregunta si es que los pobres a quienes se les proclama felices por la posesión del Reino, se considerarán de la misma manera!

La versión de Lucas ve la realidad social desde la óptica religiosa como un valor positivo, e interpreta así un hecho que en sí es ambiguo. Porque la carencia como tal es algo negativo que no supone necesariamente una actitud interior que revierta esa negatividad para hacerla un signo positivo de relación con Dios. El pobre y necesitado puede muy bien estar más interesado por salir de esa situación que por la posesión de un valor religioso que no cambia su situación.

Es cierto que el pobre puede interpretar su situación a la luz de la fe y unir de este modo la limitación de sus posibilidades de acción y posesión a una actitud interior de apertura y de aceptación de su precariedad. En un caso tal su riqueza interior es el valioso obsequio que le ha brindado la carencia exterior. Todo esto puede darse, pero sería ingenuo suponerlo de antemano. El contacto con personas realmente pobres e indigentes muestra que en ese estado se esconde a veces la impotencia y el despecho de no poseer. En esos casos sólo la facticidad de la carencia separa de la riqueza y avidez, pero la actitud con respecto a la posesión es la misma.

Si Lucas despeja la ambigüedad de la realidad social de la pobreza por medio de una interpretación teológica general que no admite casuística, se puede decir que también Mateo lo hace, pero por otro camino. La versión de Mateo no deja aparecer la ambigüedad. Si se nombra a los pobres es para inmediatamente precisar que esa realidad social en sí no es determinante para la bienaventuranza, sino en la medida en que está refrendada por una actitud interior que le da su valor propiamente religioso. Los pobres son los pobres en el espíritu, aquellos "anawim" del Antiguo Testamento que se han despojado de todas las pretensiones y olvidado los propios méritos para esperarlo todo de Dios. A ellos les pertenece el Reino de los cielos porque en ellos se concretiza el misterio de la gracia de Dios que obra la salvación y que exige del hombre la receptividad de quien se sabe necesitado de esa salvación e incapaz de llegar a ella por sus propios medios.

La expresión "pobres de espíritu", que Mateo utiliza no tiene un equivalente exacto en el Antiguo Testamento. Hay formas análogas, pero no más que ello (Sal 33, 19; Is 57, 15; etcétera). El paralelo más cercano es un texto de Qumran: 1 QM 14, 7. Los "anawim" son aquéllos de espíritu

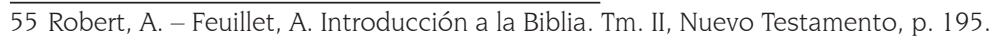


humilde, son los opuestos a los arrogantes y orgullosos (1 OS 11, 1). ${ }^{55}$

Dentro de la complejidad de la literatura rabínica hay una interpretación de la pobreza que a veces se pone en relación con la versión de la bienaventuranza de Mateo. Los "pobres en el espíritu" serían de acuerdo a esto los pobres en conocimiento, especialmente en lo referente al conocimiento de la ley. Es el "pueblo de la tierra", que es maldecido por su desconocimiento de la ley ( Jn 7, 49).

Estas dos interpretaciones, afirma J. Jeremías ayudan a concretizar lo dicho antes en forma muy general sobre los "anawim" del Antiguo Testamento. La pobreza interior puede manifestarse en modos diversos: humildad, falta de conocimiento, limitación personal. Entonces ¿A qué aspecto hace referencia Mateo en la bienaventuranza a los pobres en el espíritu? Es verdad que las bienaventuranzas ubicadas al comienzo del sermón de la montaña tienen un valor programático como proyecto de existencia cristiana. Pero esto no excluye la posibilidad de que Mateo tenga en vista una realidad mucho más inmediata y cercana relacionada con la vida de la comunidad en la que vive y a la que escribe. Aclarar esta cuestión permitirá precisar los rasgos de los pobres en el espíritu a los que se proclama feliz, y dejará entrever el trasfondo histórico que llevó al evangelista a modificar el texto de la bienaventuranza recibido de la tradición en la forma en que lo hizo.

En el así llamado "discurso comunitario" del capítulo 18 Mateo reúne textos y tradiciones de diversa procedencia. Su objetivo es exhortar a la comunidad en dos temas: el cuidado por los pequeños (Mt 18, 1 14) y la práctica del perdón dentro de la comunidad (Mt 18,15-35). Nos limitaremos a hacer referencia al primer tema, el cuidado de los pequeños.
En la unidad redaccional Mt 18, 1-14 se habla en tres ocasiones de los "pequeños". En el v. 6 se amenaza duramente a quien escandalice a uno de esos pequeños que creen en Jesús. El término "pequeños" designa en este contexto a los niños ya mencionados en la perícopa anterior (v. 1-5). De acuerdo a la afirmación de Jesús estos niños constituyen el ideal del creyente: "En verdad os digo, si no os convertís y os volvéis como niños no entraréis en el Reino de los cielos. Quien se haga pequeño como un niño, éste es el mayor en el Reino de los cielos. Y quien recibe a uno de estos pequeños en $\mathrm{mi}$ nombre, me recibe a mí" (v. 3-5).

En el v. 10 se exhorta a la comunidad a no despreciar a ninguno de esos pequeños. El motivo que se aduce remarca el valor especial de estos "pequeños": "Os digo que sus ángeles en el cielo miran continuamente el rostro de mi Padre que está en los cielos". Esta misteriosa y paradójica unión del cielo y la tierra en la persona de los "pequeños" exige que se los respete.

En el v. 14 finalmente, se afirma que es voluntad del Padre que no se pierda ninguno de los pequeños. A ellos se les aplica la parábola de la oveja perdida (M t 18, 12-13; cfr. Lc 15, 4-7), pero ahora no se entiende como reflejo de la alegría que reina en el cielo por la conversión de un pecador, sino como prueba de la voluntad salvadora del Padre con respecto a los pequeños.

La alusión tan clara a los "pequeños" en el contexto del discurso a la comunidad hace poco probable que el término sea sólo una designación genérica. El tono exhortativo y la seria advertencia ante la posibilidad de escandalizarlos y despreciarlos se entiende mejor si es que con ellos se designaba un grupo determinado en la comunidad al que vale la atención 
y la preocupación del evangelista. Esos "pequeños" no son los más fuertes en la comunidad. Pueden caer si se les escandaliza, pueden llegar a ser menospreciados por otros miembros más importantes. Pero en su aparente "insignificancia" el evangelista ve una forma de existencia cristiana en la que la acción de Dios se hace particularmente presente. Pues esos pequeños son el ejemplo viviente de la pobreza radical del hombre ante Dios. Y es justamente esa pobreza la que hace diáfana la obra de Dios.

El texto con el que finaliza el discurso de la misión de los discípulos (Mt 10, 1-42) confirma la hipótesis de explicación que proponemos. El trozo final dice (v. 41 -42): "Quien recibe a un profeta porque es un profeta, recibirá la recompensa de un profeta. Quien recibe a un justo porque es un justo, recibirá la recompensa de un justo. Y quien dé de beber a uno de estos pequeños tan sólo un vaso de agua fresca porque es un discípulo, en verdad os digo, no perderá su recompensa". El orden en que se nombra a los misioneros de la comunidad es significativo. Hay profetas y justos que si son acogidos teniendo en cuenta su especial carisma y dignidad no dejarán sin recompensa a quien hace el acto de hospitalidad. Los "pequeños" en cambio no pueden aducir otra cosa más que el ser discípulos de Jesús. Pero el que los reciba debe saber que también tendrá su recompensa.

Saquemos las conclusiones de las observaciones precedentes. El evangelista conoce ciertamente la tradición veterotestamentaria de los "anawim", de los pobres que ama Yavé (cfr. Sal 40,18; 86,1; 109,22; Jer20, 13; Is 11,4; 49,13, etcétera). Como creyente proveniente del judaísmo y dirigiéndose a una comunidad en la que prevalecen los judío-cristianos interpreta la bienaventuranza a los pobres que él recibe de la mencionada colección de dichos del Señor ("O") a la luz de esa tradición. El contorno social es diferente del que habíamos detectado en Lucas. En la comunidad de Mateo pareciera que no se plantea el problema de cristianos en posesión de bienes cuantiosos.

Pero la interpretación que da a la bienaventuranza no es fruto solamente de una opción teológica. Detrás de su teología hay una experiencia eclesial. En la comunidad hay cristianos débiles que son tenidos en poco por otros miembros más "valiosos". Identificando a los "pequeños" con los niños -el tema de los niños tiene su origen ciertamente en Jesús mismo- el evangelista invierte el orden de valores que algunos pretendían imponer, y presenta a los "pequeños" como destinatarios privilegiados de la solicitud de Dios. Así puede pensarse que los pobres "en el espíritu" están ante todo representados por este grupo de su comunidad. Ellos encarnan el ideal de existencia creyente. Es por esto que a ellos pertenece el Reino de los cielos.

\section{La Bienaventuranza a los pobres en labios de Jesús}

Lo analizado hasta ahora quizá de manera limitada nos muestra que no hay ningún motivo serio como para no atribuir la bienaventuranza a los pobres a Jesús mismo. El desarrollo de la tradición revela más bien la preocupación de interpretar la bienaventuranza en un nuevo contexto, pero esto supone la existencia de una tradición dada que se respeta y actualiza. No hay ninguna etapa en la evolución de la tradición que lleve a suponer un origen post-pascual de la bienaventuranza a los pobres.

El sentido de esta palabra en labios de Jesús no se aclara por un análisis meramente semántico de los términos. La misma afirmación puede tener signi- 
ficados muy distintos según el contexto histórico en el que se hace.

\subsection{Contexto y trasfondo socio - re- ligioso}

La realidad sociológica de Palestina en tiempos de Jesús estaba marcada por un grave problema social. Diversas causas habían contribuido a crear una situación de pobreza extendida en buena parte de la población. Hay que tener en cuenta que el reinado de Herodes (37-4 a.C.) había dejado una herencia de miseria de la que la población en el tiempo siguiente no se pudo recuperar. A esto hay que agregar una serie de desgracias naturales que acentuaron los efectos negativos de la mala administración. Flavio Josefo narra que en el año 25/24 a.C. hubo una gran escasez: una fuerte sequía dejó a la tierra casi estéril. Como consecuencia de la mala alimentación aparecieron enfermedades y epidemias. También la cosecha siguiente fue un fracaso. El fenómeno se repite en el año 46/47 d.C., lo cual muestra la inestabilidad de la estructura económica ${ }^{56}$.

No como consecuencia directa de esa situación económica pero termómetro indicador de la inseguridad social eran los movimientos políticos de protesta. Es muy revelador que los comienzos del movimiento zelota coincidan con la acción de Judas Galileo en contra de la realización de un censo (cfr. Hech 5, 37. A él se refiere probablemente (Lc 2, 1-2), a fines de controlar mejor el pago de los impuestos. Igualmente significativo es la destrucción del archivo de Jerusalén durante la guerra judía. Según Flavio Josefo el objetivo era destruir las listas de deudores, y de esta manera ganarse la simpatía de los pobres y endeudados. Esto quiere decir que el intento de liberación en contra del poder romano tenía una motivación no sólo religioso-política, sino también social: los zelotes contaban con el apoyo de los muchos pobres y sin esperanza que ya no tenían nada que perder en el cuadro social en el que se movían. Algunas palabras de Jesús dejan ver con claridad esta realidad de una sociedad necesitada que debe conformarse con el mínimo para subsistir. El horizonte imaginario de Jesús está enriquecido por su experiencia cotidiana. Con este material plasmará el contenido de sus parábolas y comparaciones que obviamente son difíciles suponer que alguien que posea una capacidad de percepción tan aguda no sea un "realista", en el sentido de que mira la realidad de su mundo tal como es.

Con esto hemos insinuado algunos aspectos de la realidad social que sirve de marco a las Palabras de Jesús. Hay otro aspecto que complementa lo anterior, y es el modo de vivir de Jesús y del grupo que lo acompaña.

Desde un punto de vista sociológico se trata de un grupo de desarraigados que no vive de acuerdo a las normas sociales de entonces. No son los únicos que viven así: en lo que hace el desarraigo comparten el modo de vivir de grupos políticos marginados, de grupos de mendigos y de enfermos como los leprosos. La palabra de Pedro a Jesús según Mc 8, 28 no es ninguna exageración: "Mira, nosotros lo hemos dejado todo y te hemos seguido". Pues para el grupo de discípulos más cercanos la posibilidad de subsistencia estaba ligada al trabajo y a la existencia junto al lago de Genesaret. Eran pescadores, no eran jornaleros, pero por su oficio eran dependientes del contorno geográ fico determinado por el lago de Galilea. $\mathrm{Al}$ abandonar este contorno abandona la propia seguridad y pasaban a depender

56 Lohse, Eduard. Op.Cit, pp127 - 130. 
de los simpatizantes con el movimiento o de quienes se compadecieran de su indigencia.

Así se entiende la radicalidad del llamado al joven rico y la exigencia de venderlo todo para seguir a Jesús (Mc 10, 17-22). Compartir la vida con Jesús quería decir también compartir su indigencia (cfr. Lc 9,58: "Los zorros tienen sus madrigueras y los pájaros del cielo sus nidos, pero el Hijo del Hombre no tiene dónde reclinar su cabeza"). Es cierto que Jesús no exige este modo de vida de todos los que aceptan su mensaje. Pero seguir a Jesús en su condición itinerante es sólo posible si se renuncia a la propia posesión y se acepta vivir en la dependencia.

Hay que remarcar que ni Jesús ni los que lo acompañan pertenecen propiamente a la clase de los pobres. Jesús proviene de una familia en la que el padre era artesano, lo que aseguraba una relativa independencia económica. Probablemente él también aprendió ese oficio como era costumbre en Palestina.

Tampoco los pescadores reclutados en el lago de Genesaret pertenecen a los pobres e indigentes. También el trabajo de pescador brindaba una apreciable seguridad social. De Zebedeo se dice que se queda con su barca y con los jornaleros que lo ayudaban, después que sus hijos Juan y Santiago lo dejan para seguir a Jesús (Mc 1, 16-20). Una motivación exclusivamente religiosa para abandonar el lugar de trabajo, la familia y renunciar a los propios bienes se da también en el grupo de Qumran. Según la Regla de la Comunidad el candidato debe pasar todo un año de prueba -algo así como un noviciado antes que sus bienes sean registrados por un encargado, pero la comunidad no puede hacer aún uso de ellos hasta que se concluya el segundo año de prueba. Recién entonces el candidato pertenece a la comunidad, a la que brinda su inteligencia, su fuerza y sus bienes.

La forma de vida en Qumran tiene más semejanza con el monacato cristiano que con el estilo de vida de Jesús y sus discípulos. Estos no viven de acuerdo con las reglas de juego de la sociedad establecida, pero no se apartan completamente de ella como la comunidad de Qumran. Lo valioso de la comparación de ambos grupos es que muestra el ideal de pobreza voluntaria y de renuncia a los propios bienes como algo común a grupos con marcada conciencia escatológica: ellos forman la comunidad del fin de los tiempos.

Si Jesús adopta una forma de vida semejante y la impone como condición para seguirlo en su camino, hay que suponer que esto no es un hecho aislado ni casual. La conciencia escatológica, es decir la certeza de vivir un momento decisivo en una historia que llega a su fin, está unida en este caso al anuncio de la llegada del Reino. No se trata con ello de ninguna estructura sacral o teocrática. Sería demasiado poco. La cosa es mucho más fundamental. El Reino quiere decir que Dios reina, que El revela su poder salvador. El anuncio de la llegada del Reino no espera ante todo un hecho espectacular, sino proclama la revelación del poder salvador de Dios a la que el hombre debe responder desde el presente de su historia. Aunque el marco de pensamiento es el de la apocalíptica judía, no hay lugar para especulaciones sobre el cuándo y el cómo de la llegada del Reino. Lo importante es la conversión de vida como respuesta a ese anuncio.

Jesús y sus discípulos son el símbolo real y eficaz de que el anuncio del Reino no es ninguna abstracción. Así como ya con el anuncio de la llegada del Reino debe comenzar ya su realización -en los signos salvíficos que atestiguan que allí obra el poder salvador de Dios-, así también se 
realiza en Jesús y sus acompañantes la verdad de la generosidad y del cuidado solícito del Padre. Su modo de vivir hace presente esta realidad. La renuncia a "ganarse la vida" en forma usual por medio del trabajo, la renuncia a los propios bienes, significan que el cuidado del Padre mantiene en vida, sin que el hombre tenga que "ganársela", y que la verdadera riqueza del hombre no consiste en lo que posee sino en su apertura y disponibilidad para ponerse al servicio del Reino.

El poder transformador del anuncio del Reino se extiende no sólo al grupo que sigue a Jesús. También el grupo de simpatizantes testimonia a su modo la vigencia del mensaje. Ellos canalizan la ayuda de Dios, son otra prueba de la preocupación del Padre por aquéllos que se han confiado totalmente a su amor protector.

La conducta de Jesús no es sin paralelos ni antecedentes en la historia de Israel. La analogía más cercana la brindan las acciones simbólicas con las que los profetas expresaban contenidos determinados de su mensaje. La mujer infiel de Oseas se vuelve signo de la infidelidad de Israel frente a Yavé (Os 1-3). El andar de Isaías desnudo y descalzo por las calles de Jerusalén simboliza el castigo inmediato. Del mismo modo hace Jesús una acción simbólica cuando llama a los doce discípulos -son el nuevo Israel del fin de los tiempos- y cuando vive con ellos como predicador itinerante sin medios propios de subsistencia.

Lo dicho hasta aquí ayuda a comprender la situación de los pobres en Palestina y el significado de la renuncia a los bienes en el grupo de Jesús. Pero la bienaventuranza a los pobres no queda explicada por estos elementos.

Ni la versión de Mt 5, 3 ni la de Lc 6, 20b permiten conocer el contexto histórico en el que Jesús pronunció esta palabra. Tanto el "sermón montano" de Mateo como el "discurso en el llano" de Lucas son construcciones redaccionales de los evangelistas en las que ellos crean un marco histórico que posibilite la transmisión del mensaje de Jesús. Pero si consideramos el texto de Lucas como el más original -y a esto nos había llevado el análisis previo- se abre un camino de comprensión. Aquí los pobres son personas a quienes se dirige el discurso. Se trata de la pobre gente que se sentía atraída por la persona y la Palabra de Jesús. Son parte de la muchedumbre o del gentío del que tantas veces se habla en los Evangelios. Aunque haya aquí mucho de redaccional, queda como base que la aparición de Jesús despertó el interés y el entusiasmo de la población de Galilea. En un tiempo de inseguridad y de grandes expectativas religiosas y políticas no es sorprendente que una figura carismática de la magnitud de Jesús haya movido a la gente a escucharlo, a llevarle enfermos, a depositar en él una esperanza tan fuerte como elemental.

\section{A Modo de Conclusión}

Después de haber realizado un análisis y unas reflexiones en torno a la bienaventuranza a los pobres, se llega a algunas conclusiones dentro del contexto cristiano actual:

1. La correcta interpretación del contenido de la Bienaventuranza a los pobres exige la consideración del contexto histórico en el que tuvo su origen la expresión. La intención de la Bienaventuranza no apunta a solucionar un problema social. Por lo tanto no se trata de un "falso" consuelo para los pobres ni de una ingenua apreciación de la realidad. Es la conciencia del presente de la salvación en la historia la que lleva a Jesús a ver en los pobres los 
destinatarios predilectos de la acción de Dios.

2. La bienaventuranza a los pobres no excluye al creyente de ningún modo de su responsabilidad social. Esto es evidente en los casos de miseria que amenazan abiertamente la dignidad de la persona y sus condiciones y posibilidades de vida, pero esa responsabilidad comienza ya en el deber de denunciar y combatir la injusticia y la explotación de los necesitados en todas sus formas. Por ello nos recuerda el documento final de Aparecida: "Las agudas diferencias entre ricos y pobres nos invitan a trabajar con mayor empeño en ser discípulos que saben compartir la mesa de la vida, mesa de todos los hijos e hijas del Padre, mesa abierta, incluyente, en la que no falte nadie. Por eso reafirmamos nuestra opción preferencial y evangélica por los pobres."

"Nos comprometemos a defender a los más débiles, especialmente a los niños, enfermos, discapacitados, jóvenes en situaciones de riesgo, ancianos, presos, migrantes. Velamos por el respeto al derecho que tienen los pueblos de defender y promover "los valores subyacentes en todos los estratos sociales especialmente en los pueblos indígenas" (Benedicto XVI, Discurso Guarulhos No 4). Queremos contribuir para garantizar condiciones de vida digna: salud, alimentación, educación, vivienda y trabajo para todos"57.

3. La bienaventuranza a los pobres revela en forma definitiva la dignidad del pobre. En una sociedad cada vez más orientada a identificar y medir valores en términos de posesión, los pobres encarnan un "anti -valor". La Palabra de Jesús, que revela los "valores de Dios" y de la nueva realidad del Reino, hace posible que los pobres se reconozcan en su propio valor y dignidad, y no sucumban a la tentación de imitar y asumir los valores "normales", como la posesión y la riqueza.

4. Sin olvidar la concretez con la que aquí se habla de los pobres es posible ver en ellos un ideal de existencia cristiana que sobrepasa los límites de una consideración simplemente sociológica de la pobreza. En este sentido los pobres son aquéllos que "nada quieren y solamente una cosa necesitan: poder ser tan pobres como realmente lo son"58.

Para culminar estas reflexiones no podemos dejar de lado las palabras tan enriquecedoras de Juan Pablo II: "Bienaventurados los pobres de espíritu (Mt 5,3). Esta es precisamente la primera de las ocho bienaventuranzas que proclamó Jesús en el sermón de la montaña.

Los pobres de espíritu son aquellos que están más abiertos a Dios y a las maravillas de Dios. Pobres, porque están siempre dispuestos a aceptar ese don de lo alto, que proviene del mismo Dios. Pobres de espíritu son los que viven conscientes de haberlo recibido todo de las manos de Dios como un don gratuito y que valoran cada uno de los bienes recibidos. Constantemente agradecidos, repiten sin cesar: 'Todo es gracia', 'demos gracias al Señor nuestro Dios... los corazones abiertos a Dios están, por eso mismo, más abiertos a los hombres. Están dispuestos a ayudar desinteresadamente. Dispuestos a compartir lo que 
tienen. Dispuestos a acoger en su casa a una viuda o a un huérfano abandonados. Siempre encuentran un lugar disponible dentro de las estrecheces en que viven. Y encuentran también siempre un poco de alimento, un pedazo de pan en su pobre mesa. Pobres pero generosos. Pobres, pero magnánimos"59.

Así, pues, pobres de espíritu son aquellos que, careciendo de bienes terrenales, saben vivir con dignidad humana los valores de una pobreza espiritual rica de Dios; y aquellos que, poseyendo los bienes materiales, viven el desprendimiento interior y la comunicación de bienes con los que sufren necesidad.

De los pobres de espíritu es el reino de los cielos. Esta es la recompensa que Jesús les promete. No se puede prometer más. Esta bienaventuranza que, en cierto sentido, comprende todas las demás, hemos de proyectarla sobre los pobres reales, teniendo en cuenta todas las clases y formas de pobreza que existen en nuestro mundo y mirando también a tantos hombres ricos que son terriblemente pobres (Radiomensaje de Navidad, 1984). También hace eco el actual Papa Benedicto XVI, al manifestarnos: "En el mundo de hoy se da el fenómeno de la globalización como un entramado de relaciones a nivel planetario. Aunque en ciertos aspectos es un logro de la gran familia humana y una señal de su profunda aspiración a la unidad, sin embargo comporta también el riesgo de los grandes monopolios y de convertir el lucro en valor supremo. Como en todos los campos de la actividad humana, la globalización debe regirse también por la ética, poniendo todo al servicio de la persona humana creada a imagen y semejanza de Dios"60.

\section{REFERENCIAS}

Aparecida. Documento final. (2007). V conferencia general del Episcopado Latinoamericano y del Caribe. Lima, Edic. San Pablo.

Biblia de Jerusalén. (1975). Desclee de Brouwer, Ed. Española.

Chevrot, Georges. (1989). Las bienaventuranzas, Madrid, Edit. Rialp S.A.

De La Calle, Francisco. (1978). Aproximación a los evangelios. Madrid, Edit. Marova.

Hengel, Martín. (1978). El Hijo de Dios, el origen de la cristología y la historia de la religión judeo - helenista. Salamanca, Edic. Sígueme.

Jeremías, Joachim. (1989). ABBA, el mensaje central del Nuevo Testamento. Madrid, Edic. Sígueme.

Juan Pablo II. (1985). Discursos - Mensajes en el Perú. Lima, Edit. Studium.

Lona, Horacio. (1998). Las bienaventuranzas. Argentina, Edit. Don Bosco.

Lohse, Eduard. (1998). Introducción al Nuevo Testamento. Madrid, Edic. Cristiandad.

Maté Rico, Antonio. (1996). Palabra de Dios. Madrid, Edit. Lattergarf.

Robert A. - A. Feuillet. (1967). Introducción a la Biblia. Tm. II, Nuevo Testamento. Barcelona, Edit. Herder.

Ruiz de La Peña, Juan. (1986). La otra dimensión. Santander, Edit. Sal Terrae. 